\title{
Lessons learned with the Cobra prosthesis in elderly patients with complex distal radius fractures-a retrospective follow-up study
}

\author{
Stefan Benedikt ${ }^{1} \cdot$ Peter Kaiser $^{1} \cdot$ Gernot Schmidle $^{1} \cdot$ Tobias Kastenberger $^{1} \cdot$ Kerstin Stock $^{1} \cdot$ Rohit Arora $^{1}$ (i)
}

Received: 28 May 2021 / Accepted: 26 July 2021 / Published online: 2 August 2021

(c) The Author(s) 2021

\begin{abstract}
Introduction Recently, the Cobra prostheses were introduced in the treatment of distal radius fractures (DRF) of elderly patients. Fracture prostheses provide an alternative treatment option for complex fractures where conservative therapy seems not acceptable and osteosynthesis seems not possible. Data reporting the feasibility of the Cobra prosthesis are sparse. Therefore, this retrospective follow-up study investigated the clinical and radiological mid-term outcome of the Cobra implant in complex DRFs of elderly patients.

Materials and methods Thirteen patients (mean age 73.5 years, range 65-87 years) were retrospectively evaluated with at least a 1-year follow-up after surgery. Objective and subjective clinical parameters as well as the radiological outcome and complications were analyzed.

Results The mean follow-up period was 31.2 months. Seven cases required a cemented prosthesis. The mean relative rangeof-motion compared to the healthy side was $72.3 \%$ and $51.8 \%$ for extension and flexion, respectively, and $87.9 \%$ and $85.7 \%$ for pronation and supination, respectively. The mean grip strength was $78.3 \%$ compared to the non-operated side. Eight patients were very satisfied, five patients were partly satisfied with the result. The DASH, PRWE, MHQ and Lyon-Scores averaged 39.1, 36.2, 64.9 and 63.3 points, respectively. The mean VAS-Score for pain was 1.1 at rest and 3.2 during activities. Perioperative complications included one dissection of the extensor pollicis longus tendon, one heterotopic ossification, one radiocarpal dislocation and two cases of an ulnar impaction syndrome due to implant subsidence.

Conclusion The prosthetic treatment of complex DRFs in elderly patients with the Cobra implant led to clinically and radiologically satisfactory mid-term results. The Cobra prosthesis still does not represent a gold standard but can be regarded as a feasible salvage option for complex DRFs when osteosyntheses may not be possible and non-operative treatment will lead to further functional restrictions and wrist pain during performing activities of daily life in high functional demand patients.
\end{abstract}

Keywords Fracture $\cdot$ Hemiarthroplasty $\cdot$ Wrist $\cdot$ Geriatric $\cdot$ Salvage $\cdot$ Osteoporosis

Rohit Arora

rohit.arora@i-med.ac.at

Stefan Benedikt

stefan.benedikt@tirol-kliniken.at

Peter Kaiser

peter.kaiser@tirol-kliniken.at

Gernot Schmidle

gernot.schmidle@tirol-kliniken.at

Tobias Kastenberger

tobias.kastenberger@tirol-kliniken.at

Kerstin Stock

kerstin.stock@tirol-kliniken.at

1 Department of Orthopaedics and Traumatology, University Hospital Innsbruck, Anichstraße 35, 6020 Innsbruck, Austria

\section{Introduction}

Distal radius fractures (DRF) are the second most common fractures among elderly patients over 65 years of age. They are mainly caused by a fall from standing height associated with a decreased bone mineral density [1]. Open Reduction and Internal Fixation (ORIF) is a well-established treatment option for those patients. With the advent of volar locking-plate systems and fragment specific fixation, surgeons have improved options for stable fixation of comminuted intra-articular fractures in osteopenic bone [2-6]. However, loss of reduction as well as intra-articular screw penetration with very distal fractures can still occur leading to malunion, osteoarthritis and clinical failure $[7,8]$. On the other hand, low demand 
elderly patients often do well with nonoperative management of distal radius fractures even those with residual displacement $[9,10]$.

In severely comminuted cases of complex intra-articular fractures, surgical treatment with plate fixation and/ or external fixation may not be possible and non-operative treatment may not be acceptable. In 2009, Roux [11] published first results of a wrist hemiarthroplasty with the SOPHIA implant (Biotech, Paris, France) as an alternative treatment option for complex DRFs with a severely destroyed radial joint surface in elderly patients. The more bone-sparing Cobra implant (Groupe Lépine, Lyon, France) was presented by Herzberg in 2015 [12]. Several further studies showed moderate short-term and mid-term results (3-127 months), so that primary hemiarthroplasty is currently seen as a salvage option rather than an accepted standard [11-20]. However, data reporting the clinical outcome are rare. Potentially some bias may emerge, because several reports mixed different prostheses designs in the clinical outcome measurement. Additionally, the inventors of the SOPHIA and Cobra prostheses, respectively, conducted all studies but one.

The aim of this retrospective follow-up study was an evaluation of the clinical and radiologic mid-term results of elderly patients treated with the Cobra prosthesis (Groupe Lépine, Lyon, France) for multi-fragmented intra-articular distal radius fractures with an irreparable joint surface.

\section{Patients and methods}

Approval for conducting this study was obtained by the institutional review board. Fourteen patients ( 73.5 years, SD 6.5, minimum 65 years, maximum 87 years, 1 male, 12 females) with a DRF were treated using a hemiarthroplasty between April 2015 and March 2019 at our institution. One patient had already deceased because of a medical condition not associated to the trauma. The remaining 13 patients could be included into this retrospective analysis and were seen for a mid-term follow-up at least 1 year after surgery (on average 31 months, range $12-54$ months).

Indication for primary hemi-arthroplasty was set by an experienced hand surgeon in cases of unreconstructable comminuted AO-C3 fractures with distal fracture crossing the watershed line, separated palmar and dorsal fragments, impaction of the central joint surface and metaphyseal comminution. Additionally, the patients had to be aged 65 years or older and living at home performing activities of daily living independently. Surgical treatment was based on the technique described by Herzberg et al. [12, 21]. A longitudinal incision was made dorsally in line with the third metacarpal bone (Fig. 1a). The distal radius was accessed through the third extensor compartment. With an osteotome a longitudinal split of the radius was placed medial to the Lister tubercle up to the distal diaphysis and a radial and an ulnar osteoperiosteal flap were raised similar to opening a book (Fig. 1b). The radial part contained the second and the
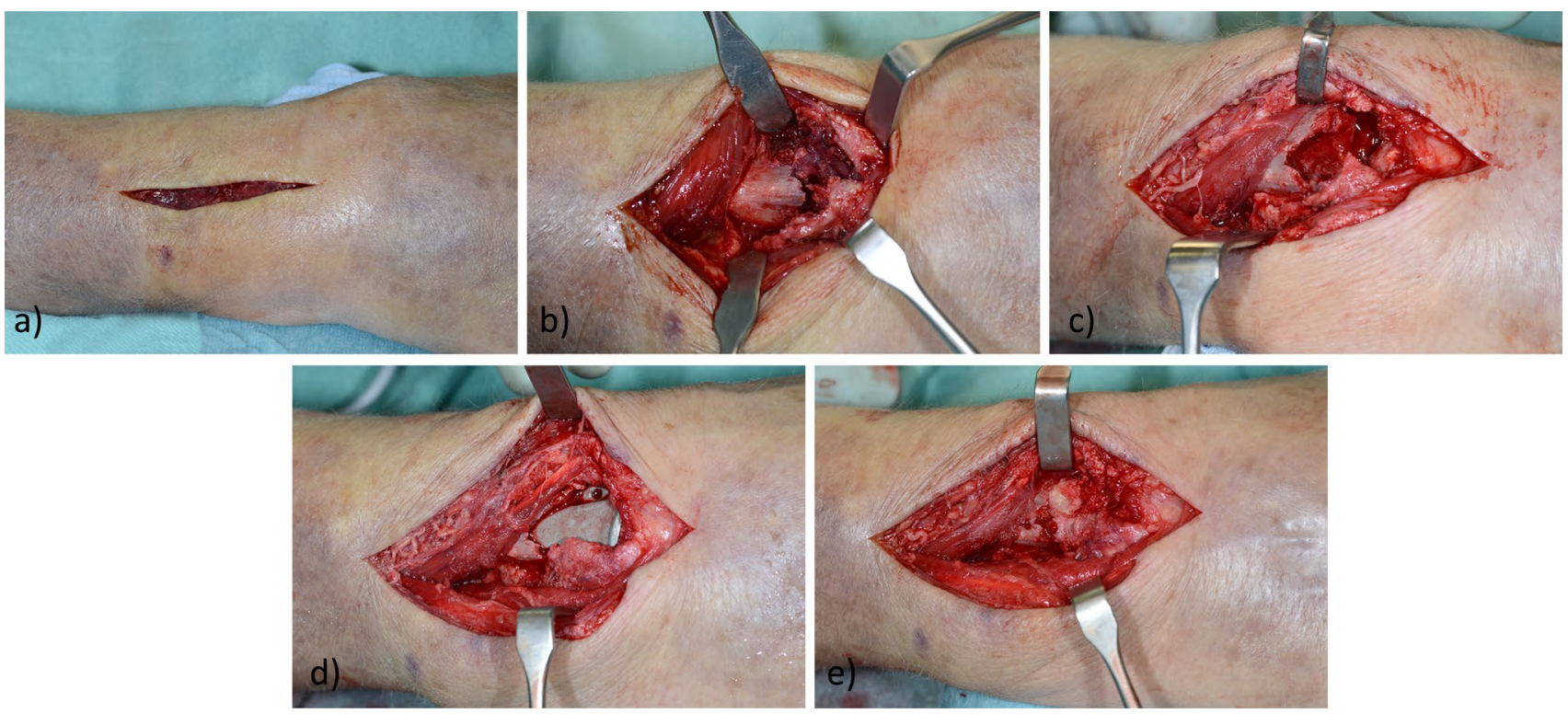

Fig. 1 a Longitudinal dorsal approach in line with the third metacarpal bone. b Access to the comminuted distal radius by raising two osteoperisoteal flaps in an opening-book like fashion. c Distal radius after resection of the articular surface and the central epiphyseal can- cellous bone and after broaching according to the preoperative planning. d Situation after implantation of the final prosthesis and reduction of the carpus. $\mathbf{e}$ The osteoperiosteal flaps brought back together 
ulnar flap the fourth extensor compartment. A denervation was performed of the dorsal interosseus nerve. The articular surface of the distal radius and the central epiphyseal cancellous bone were resected. The volar, lateral and dorsal osteoperiosteal flaps of the distal radius were carefully preserved to save the bone stock and to allow bone covering of the prostheses. The wrist was then flexed to $90^{\circ}$ and the diaphysis was broached according to the preoperative planning (Fig. 1c). The trial implant was gently inserted and a reduction of the carpus on the distal implant surface was performed. The radial and ulnar flangs were used to control the rotation of the implant. In cases of a too tight or too loose implant stability, reduction corrections by broaching or by inserting cancellous bone could be performed. In case of an appropriate reduction, the final implant was gently impacted into the distal radius (Fig. 1d). Bone cement was used if the implant stem could not be fixed stably at the metadiaphyseal junction. The osteoperiosteal flaps ware brought back together, sutured together (Fig. 1e) and the wound was closed.

Procedures to the distal ulnar were indicated as following: If the sigmoid notch was reconstructable, it was re-approximated and secured with non-adsorbable sutures and the distal ulna was left intact. A Sauvé-Kapandji or a Darrach procedure (depending on the surgeon's preference) were performed in cases with severe involvement of the DRU-joint to prevent the ulnar head from erosions due to contact between implant and cartilage. For the Sauvé-Kapandji procedure a dorsal plate was used as the classical transfixation with a screw was not possible due to the position of the implant. The hemiresection-interposition technique described by Bowers [22] was not performed as it was considered not advantageous over the other procedures and authors did not want to take the risk of an impingement of the ulnar process and of a potentially associated revision in the already vulnerable patient population. In cases of open fractures, massive soft tissue swelling or other comorbidities that did not allow immediate hemiarthroplasty, a temporary external fixator was applied [23]. Postoperative treatment included cast immobilization and physiotherapy after cast removal.

Twelve cases had an irreparable DRF type AO-C3 and one case needed a secondary hemiarthroplasty after failed primary ORIF using a volar locking plate. The latter case was treated in an external hospital and was revised due to radiocarpal subluxation and consecutive joint destruction. Three patients had a grade I open DRF of whom one patient required primary treatment with an external fixator. The average time from injury to hemiarthroplasty was 9 days ( $\mathrm{SD} \pm 9$ days) excluding the one case of secondary hemiarthroplasty 125 days after the trauma. Seven cases received a cemented prosthesis. In one case, a palmar approach was used, whereas in the other patients the recommended dorsal approach was used. Six patients received additional surgical treatment at the time of hemiarthroplasty: One patient had a re-fracture of the distal radius 9 years after ORIF with a palmar plate requiring implant removal and bone grafting beside hemiarthroplasty. The other additional procedures included the implantation of a dorsoulnar plate on the radius $(n=1)$; as well as a radial plate $(n=1)$; primary SauvéKapandji procedures $(n=2)$ and a primary Darrach procedure $(n=1)$. The mean duration of surgery was $126.8 \mathrm{~min}$ ( $\mathrm{SD} \pm 55.2 \mathrm{~min}$, minimum $63 \mathrm{~min}$, maximum $250 \mathrm{~min}$ ). Postoperative splint immobilization time ranged from 3 to 5 weeks; one patient had no immobilization. The average hospitalization time was 8 days ( $\mathrm{SD} \pm 5$ days, minimum 2 days, maximum 21 days).

Detailed patient characteristics are listed in the Online Resource 1.

All patients underwent a clinical and a radiographic examination. Objective clinical parameters included the range of motion (ROM), the grip strength and the tip-topalm distance. Patients were asked to reply to a German translation of the "Disabilities of the Arm, Shoulder and Hand Score" (DASH Score), the "Patient-Rated Wrist Evaluation Score" (PRWE Score), the "Michigan Hand Outcomes Questionnaire" (MHQ), the "Lyon Score" and to indicate their pain levels on the 10-point visual analogue scale (VAS) to evaluate the subjective clinical outcome. Overall satisfaction was rated by the patients having the choice between very satisfied, partly satisfied or not satisfied. Patients were also asked whether they would undergo the same surgery again, if necessary.

The radiographic examination consisted of a standard dorsopalmar and lateral radiograph at the follow-up. Radiologic outcome parameters included signs of periprosthetic osteolysis defined as radiolucency, implant dislocation, axial subsidence, osteoarthritis (OA) and erosions in the radiocarpal and the distal radioulnar (DRU) joint according to the Kellgren-Lawrence classification as well as measurements of the dorsal tilt, the radial inclination and the ulnar variance (UV) preoperatively.

Data are presented using descriptive statistics.

\section{Results}

\section{Clinical results}

Clinical outcome parameters are summarized in Table 1. Eight patients (62\%) stated to be very satisfied and five patients (38\%) were partly satisfied with the result. All patients would undergo the same operation again if necessary.

The outcomes of patients having a Sauvé-Kapandji or Darrach procedure and of patients without intervention at the DRU joint are compared in Table 2. Patients with a 
Table 1 Clinical mid-term results after hemiarthroplasty using the Cobra prosthesis

\begin{tabular}{lll}
\hline Measurement parameters & $\begin{array}{l}\text { Mean }(\% \text { of the uninjured } \\
\text { wrist })\end{array}$ & SD \\
\hline Extension & $46^{\circ}(72 \%)$ & $10^{\circ}$ \\
Flexion & $22^{\circ}(52 \%)$ & $13^{\circ}$ \\
Radial deviation & $17^{\circ}(83 \%)$ & $10^{\circ}$ \\
Ulnar deviation & $29^{\circ}(71 \%)$ & $11^{\circ}$ \\
Pronation & $67^{\circ}(88 \%)$ & $12^{\circ}$ \\
Supination & $69^{\circ}(86 \%)$ & $17^{\circ}$ \\
Grip strength & $17 \mathrm{~kg}(78 \%)$ & $5 \mathrm{~kg}$ \\
Tip-to-palm distance & $0 \mathrm{~cm}$ & $0 \mathrm{~cm}$ \\
DASH & 39 & 24 \\
PRWE & 36 & 23 \\
Lyon & 63 & 14 \\
MHQ & $65(83 \%)$ & 15 \\
VAS resting & 1.1 & 1.5 \\
VAS working & 3.2 & 2.2 \\
\hline
\end{tabular}

$S D$ standard deviation

Table 2 Comparison of the outcome of patients having SauvéKapandji or Darrach procedure versus patients with no intervention at the DRU joint

\begin{tabular}{|c|c|c|c|c|}
\hline \multirow[t]{2}{*}{$\begin{array}{l}\text { Measurement } \\
\text { parameters }\end{array}$} & \multicolumn{2}{|c|}{$\begin{array}{l}\text { Sauvé-Kapandji or } \\
\text { Darrach } \\
n=4\end{array}$} & \multicolumn{2}{|c|}{$\begin{array}{l}\text { No ulnar intervention } \\
n=9\end{array}$} \\
\hline & $\begin{array}{l}\text { Mean (\% of the } \\
\text { uninjured wrist) }\end{array}$ & $\mathrm{SD}$ & $\begin{array}{l}\text { Mean (\% of the } \\
\text { uninjured wrist) }\end{array}$ & $\mathrm{SD}$ \\
\hline Extension & $50^{\circ}(80 \%)$ & $8^{\circ}$ & $44^{\circ}(69 \%)$ & $11^{\circ}$ \\
\hline Flexion & $11^{\circ}(31 \%)$ & $16^{\circ}$ & $27^{\circ}(59 \%)$ & $10^{\circ}$ \\
\hline Radial deviation & $9^{\circ}(64 \%)$ & $12^{\circ}$ & $21^{\circ}(88 \%)$ & $8^{\circ}$ \\
\hline Ulnar deviation & $29^{\circ}(79 \%)$ & $13^{\circ}$ & $29^{\circ}(68 \%)$ & $11^{\circ}$ \\
\hline Pronation & $61^{\circ}(85 \%)$ & $8^{\circ}$ & $69^{\circ}(89 \%)$ & $13^{\circ}$ \\
\hline Supination & $78^{\circ}(93 \%)$ & $18^{\circ}$ & $66^{\circ}(83 \%)$ & $16^{\circ}$ \\
\hline Grip strength & $15 \mathrm{~kg}(86 \%)$ & $4 \mathrm{~kg}$ & $18 \mathrm{~kg}(76 \%)$ & $5 \mathrm{~kg}$ \\
\hline $\begin{array}{l}\text { Tip-to-palm dis- } \\
\text { tance }\end{array}$ & $0 \mathrm{~cm}$ & $0 \mathrm{~cm}$ & $0 \mathrm{~cm}$ & $0 \mathrm{~cm}$ \\
\hline DASH & 52 & 25 & 33 & 23 \\
\hline PRWE & 39 & 30 & 35 & 20 \\
\hline Lyon & 69 & 9 & 61 & 15 \\
\hline MHQ & $62(90 \%)$ & 11 & $66(80 \%)$ & 16 \\
\hline VAS resting & 1.0 & 2.0 & 1.1 & 1.4 \\
\hline VAS working & 2.5 & 2.1 & 3.6 & 2.4 \\
\hline
\end{tabular}

$S D$ standard deviation

Sauvé-Kapandji or Darrach procedure achieved better results in supination, grip strength and in pain during activities (also when excluding the cases with ulnar impaction syndrome). On the other hand, flexion, radial deviation and the DASH score were worse in this group.

\section{Radiologic results}

Preoperatively, the average dorsal tilt, radial inclination and ulnar variance were $-8.9^{\circ}\left(\mathrm{SD} \pm 37.4^{\circ}\right), 8.8^{\circ}$ $\left(\mathrm{SD} \pm 8.6^{\circ}\right)$ and $6.1 \mathrm{~mm}(\mathrm{SD} \pm 4.1 \mathrm{~mm})$, respectively. Postoperatively, signs of implant loosening were detected in two cases (around the stem $n=1$; around the distal part of the implant shell $n=1$ ). Radiocarpal signs of osteoarthritis were found in six cases but were not possible to quantify due to implant-related overlaps (sclerotic signs around the scaphoid $n=3$; scaphoid erosions $n=1$; radioscaphoidal synostosis $n=1$; triquetral erosions $n=1$ ). Among the nine cases without ulnar surgery, four cases presented sings of erosion due to the implant or signs of OA in the DRU joint (DRUJ erosions $n=2$; OA grade I $n=1$; OA grade II-III $n=1$-according to the Kellgren-Lawrence Classification). Postoperative radiologic results of each patient are listed in Table 3.

\section{Complications}

No patient developed a complex regional pain syndrome (CRPS) or an infection. An iatrogenic extensor pollicis longus (EPL) tendon laceration at the time of surgery occurred in one case. Two patients needed a secondary revision following hemiarthroplasty: The first case was the patient with the palmar approach who showed radiocarpal dislocation of the prostheses postoperatively. Initially, this patient was planned for ORIF. The result of the open reduction was not acceptable and therefore a cemented hemiarthroplasty was performed from palmar. The first postoperative X-ray revealed radiocarpal dislocation requiring a secondary derotational osteotomy of the radius shaft with a Darrach procedure and a pronator quadratus muscle interposition transfer at the proximal ulna stump (Fig. 2). The other patient with a Kapandji procedure developed severe heterotopic ossifications between the ulnar head and the distal stump of the ulna causing severe restrictions in rotation. The patient was revised nine months after hemiarthroplasty by excision of the ossifications, removal of the dorsal radioulnar plate and a pronator quadratus interposition transfer. Postoperative prophylaxis was not initiated, nevertheless, recurrence of ossifications could not be observed (Fig. 3). Axial subsidence of the implant was observed in two cases of noncemented prostheses to an extent of an average of $6 \mathrm{~mm}$ (Table 3). One patient had a postoperative ulnar variance (UV) of $+2.0 \mathrm{~mm}$ postoperatively and $+6.5 \mathrm{~mm}$ at the final follow-up, the second patient had a postoperative UV of $-1.5 \mathrm{~mm}$ and $+6.0 \mathrm{~mm}$ at the final follow-up (Fig. 4). Both patients developed an ulnar impaction syndrome but did not request further surgical treatment. 
Table 3 Postoperative radiologic results of each patient

\begin{tabular}{|c|c|c|c|c|c|c|c|c|}
\hline Patient & Sex & Age (years) & $\begin{array}{l}\text { Follow- } \\
\text { up } \\
\text { (months) }\end{array}$ & Cemented & Lucencies & $\begin{array}{l}\text { Amount of } \\
\text { subsidence } \\
(\mathrm{mm})\end{array}$ & Signs of OA at the radiocarpal joint & $\begin{array}{l}\text { Signs of OA at the } \\
\text { distal radioulnar } \\
\text { joint }\end{array}$ \\
\hline 1 & $\mathrm{f}$ & 66 & 12 & No & No & 0 & n.a. ${ }^{a}$ & No \\
\hline 2 & $\mathrm{f}$ & 75 & 12 & Yes & No & 0 & Sclerotic signs scaphoid & Erosions \\
\hline 3 & $\mathrm{f}$ & 65 & 17 & Yes & No & 0 & n.a. ${ }^{a}$ & n.a. ${ }^{b}$ \\
\hline 4 & $\mathrm{f}$ & 73 & 19 & No & Around the shell & 7.5 & n.a. ${ }^{a}$ & no \\
\hline 5 & $\mathrm{f}$ & 75 & 24 & Yes & No & 0 & n.a. ${ }^{a}$ & n.a. ${ }^{b}$ \\
\hline 6 & $\mathrm{f}$ & 87 & 29 & Yes & No & 0 & Sclerotic signs scaphoid & no \\
\hline 7 & $\mathrm{f}$ & 71 & 31 & Yes & No & 0 & Radioscaphoidal synostosis & n.a. ${ }^{b}$ \\
\hline 8 & $\mathrm{f}$ & 68 & 33 & Yes & No & 0 & Sclerotic signs scaphoid & no \\
\hline 9 & $\mathrm{f}$ & 74 & 40 & No & No & 0 & Triquetral erosions & Grade $\mathrm{I}^{\mathrm{c}}$ \\
\hline 10 & $\mathrm{f}$ & 66 & 42 & No & Around the stem & 0 & n.a. ${ }^{a}$ & n.a. ${ }^{\text {b }}$ \\
\hline 11 & $\mathrm{f}$ & 76 & 54 & No & No & 0 & Scaphoid erosions & Grade II-III ${ }^{\mathrm{c}}$ \\
\hline 12 & $\mathrm{f}$ & 80 & 54 & No & No & 4.5 & n.a. ${ }^{a}$ & Erosions \\
\hline 13 & $\mathrm{~m}$ & 80 & 38 & Yes & No & 0 & n.a. ${ }^{a}$ & No \\
\hline
\end{tabular}

$O A$ osteoarthritis; n.a. not applicable

${ }^{\text {a }}$ Due to implant-related overlaps in the X-ray

${ }^{\mathrm{b}}$ After Kapandji or Darrach procedure

${ }^{\mathrm{c}}$ According to the Kellgren-Lawrence Classification
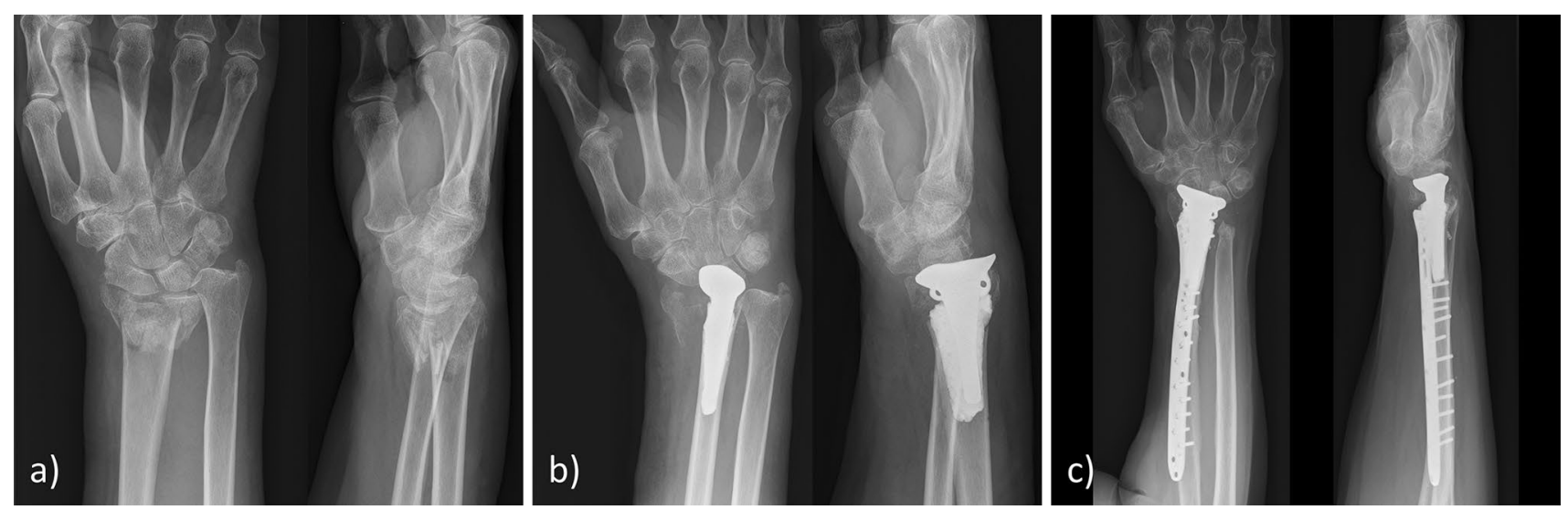

Fig. 2 a Radiograph of the initial fracture. b Radiocarpal dislocation after hemiarthroplasty from a palmar approach. Revision included derotational osteotomy with a Darrach procedure and a prona-

\section{Discussion}

The current mid-term results suggest that the Cobra prosthesis is a feasible option for complex distal radius fractures in elderly patients. The most important finding was the high satisfaction rate among all cases, with eight patients being very satisfied and five patients being satisfied with the result. All patients would also undergo the same operation again if necessary. tor quadratus interposition transfer. c Radiograph at the follow-up 16 months after revision

Encouraging objective results were achieved regarding ROM and grip strength except in flexion, which was on average $50 \%$ of the uninjured wrist. An explanation for the flexion deficit might be dorsal scar formation caused by the surgical approach. The mean VAS score showed on average mild pain with 1.1 at rest and 3.2 during activities. However, other subjective evaluation scores revealed obvious restrictions in daily life. 
Fig. 3 a Radiograph of the initial fracture. b Radiograph after hemiarthroplasty and SauvéKapandji procedure with dorsal plating. c Severe heterotrophic ossifications 4 months after surgery leading to significant functional impairment. Revision included excision of the ossifications, removal of the dorsal radioulnar plate and a pronator quadratus interposition. $\mathbf{d}$ Radiograph at the follow-up 34 months after revision
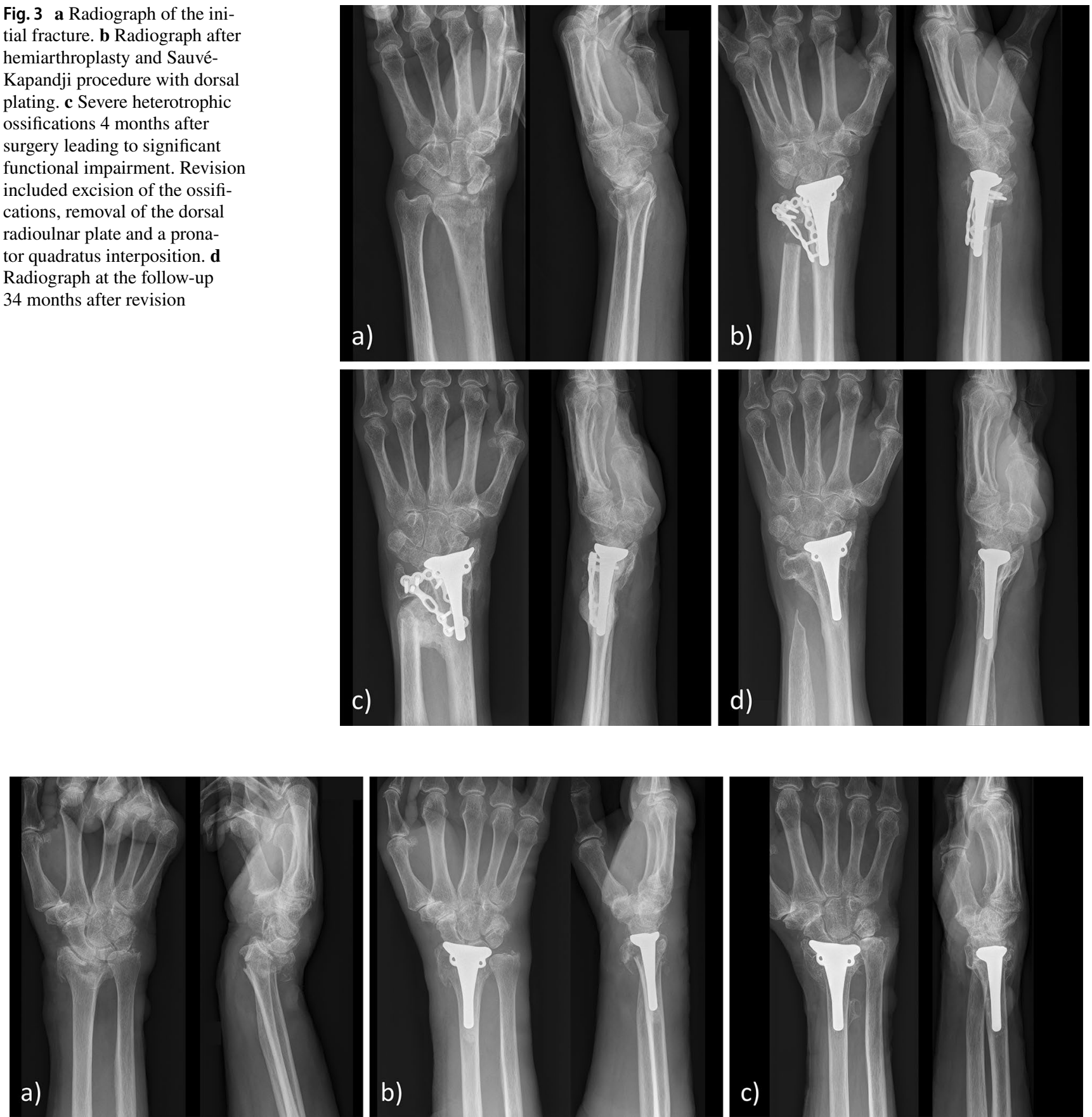

Fig. 4 a Radiograph of the initial fracture. b Radiograph after hemiarthroplasty with a non-cemented prosthesis and successful reconstruction of the distal radioulnar joint with non-adsorbable sutures showing an acceptable position of the implant with a negative ulnar

Another important finding was the axial subsidence of the implant in two of six cases of non-cemented prostheses leading to an ulnar impaction syndrome. Routine use of bone cement may probably avoid radial shortening.

A hypothesis to explain the better outcome in grip strength and pain in the ulnar intervention group might be variance of $-1.5 \mathrm{~cm}$. c Severe axial sinking with an ulnar variance of $+6.0 \mathrm{~cm}$ and clinical signs of an ulnar impaction syndrome 19 months after hemiarthroplasty

the physiological relative increase in ulnar variance during grip [24]. In combination with radial shortening caused by the fracture and the hemiarthroplasty, activities that involve repetitive grip and forearm rotation might cause pain. However, given the small sample size of the groups, it is difficult to draw a clear conclusion from this data. A disadvantage 
of the ulnar interventions is the longer surgery time. Under favorable conditions, a Cobra prosthesis can be implanted much faster. The shortest surgery time among our cases was $63 \mathrm{~min}$.

Hemiarthroplasty performed from a palmar approach has proven to be disadvantageous, as the reference points, especially regarding the rotation, for exact positioning of the implant are difficult to identify. The orientation of the prosthesis must be parallel to the anterior aspect of the radial epiphysis in the transverse plane. This can be achieved by the recommended dorsal approach more easily [21].

Recent studies showed moderate results for wrist hemiarthroplasty in elderly patients following complex DRF [11-20]. The idea of hemiarthroplasty for this indication was first implemented by Roux in 2005 [11]. The SOPHIA implant used in his patients is composed of a radial stem and an epiphyseal-metaphyseal block articulating with the carpus and the ulnar head. The clinical results of patients receiving hemiarthroplasty seem to be better and associated with a faster rehabilitation than reconstructive surgery (Table 4). The disadvantage of this design consists in a relatively large amount of bone material that has to be resected. Further, implantation is contraindicated in the event of a simultaneous fracture of the ulnar head or neck $[11,14,17]$.

Ichihara et al. [20] published a preliminary report of an Unicompartemental Isoelastic Resurfacing Prosthesis (Prosthelast, Argomedical, Cham, Switzerland) in comminuted articular DRF of osteoporotic elderly patients. The implant is designed as a joint surface replacement and is fixed with an intramedullary pin using an attachment screw. Advantages include the bone sparing properties and the intramedullary support that provides primary stabilization of the prosthesis [20]. A second report of the resurfacing prosthesis in the setting of distal radius fractures of elderly patients was published by Martins et al. [19] in 2020. Clinical results are summarized in Table 5.

In 2015, Herzberg [12] reported first results of the Cobra prosthesis for complex DRFs, which is also more bone sparing and does not require an intact distal ulna compared to the SOPHIA implant. His experiences have been described in several publications $[12,13,18]$. A direct comparison to our current data is limited, as the authors combine the results of the Cobra implant with the radial component of the Pressfit-Remotion Total Wrist implant (Small Bone Innovations, Morrsiville, PA, USA) [12, 13, 18] (Table 6).

In 2019, Anger et al. [15] published their experiences with the Cobra prosthesis in a retrospective study on eleven patients. The average age was 80.4 years, the average follow-up 18.3 months. Nine fractures were classified as C3, two were classified as $\mathrm{C} 2$ according to the AO classification. Eight patients received a cemented and three patients a non-cemented prosthesis. Two patients underwent an ulnar head resection at the time of hemiarthroplasty, one patient 6

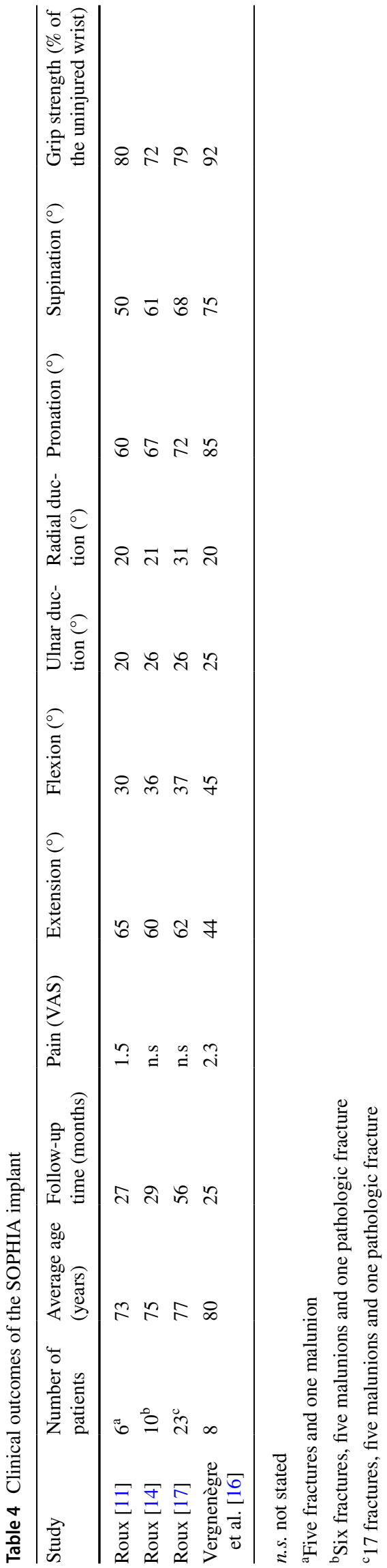




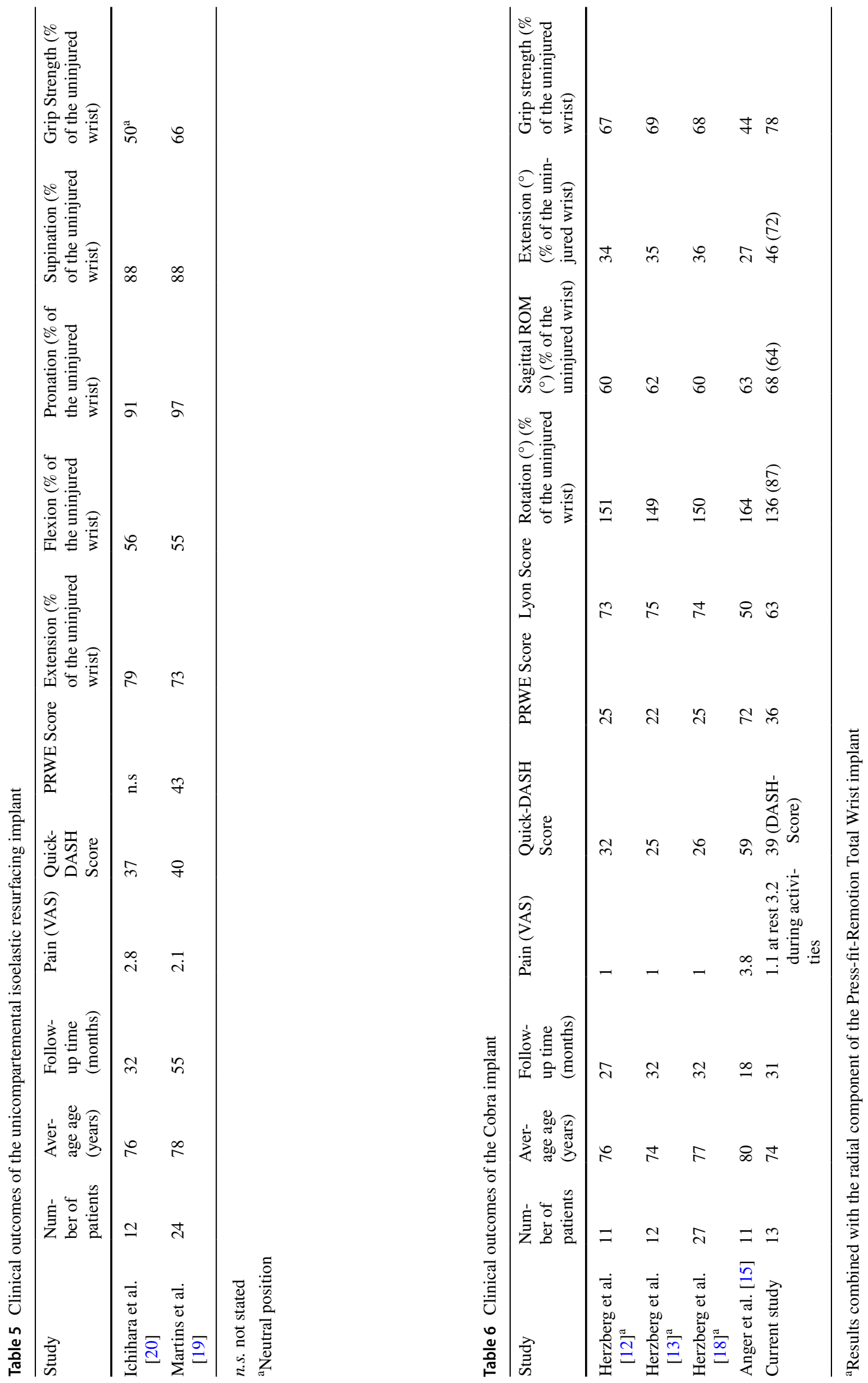


Fig. 5 a Radiograph of a periprosthetic fracture after a falling accident. b Radiograph after revision by removing the cement from the proximal fragment, implantation of an allograft and osteosyntheses with a palmar plate
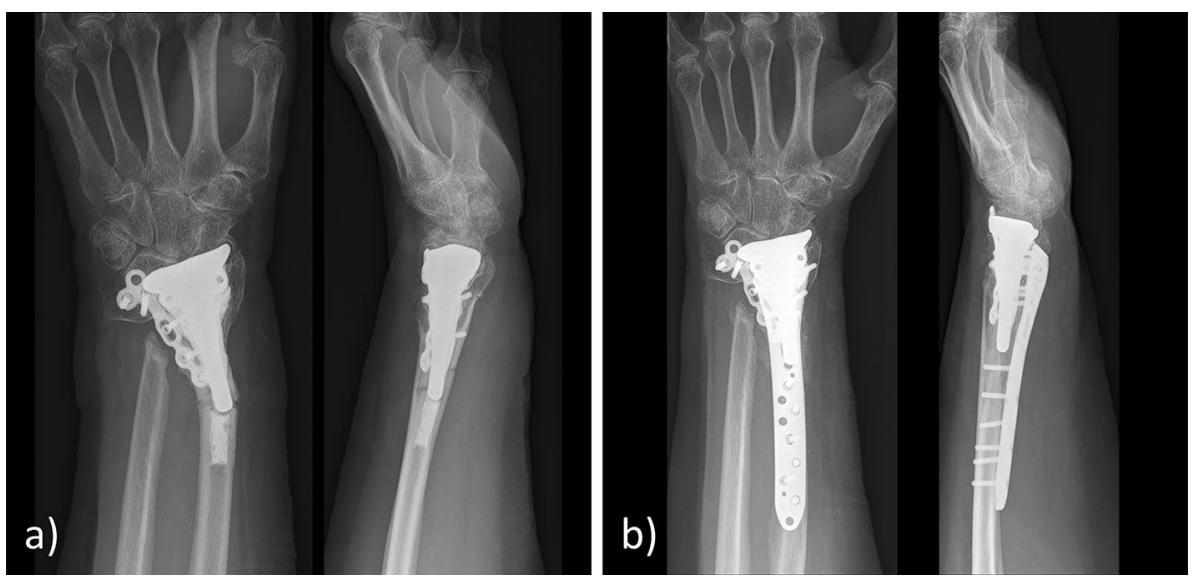

months postoperatively due to rotational pain. Two patients developed a type 1 CRPS. The clinical results are listed in Table 6. Subjectively, seven patients stated to be satisfied or very satisfied, four patients were not satisfied. Radiologically, there was neither sign for an implant displacement or loosening, nor radial or ulnar tilt of the carpus.

Our current study had a longer follow-up time compared to the study of Anger et al. [15] (18 vs. 31 months). Subjective clinical results were notably better regarding satisfaction rate and the DASH, PRWE and Lyon Scores. Average pain was lower in our study, however, a direct comparison is difficult, as we assessed the VAS scores both at rest and during activities separately. Regarding the objective outcome we observed a better grip strength ( $78 \%$ vs. $44 \%$ of the healthy opposite side). An explanation for the difference might be the lower age among our study population. Sagittal ROM was nearly equal with a better extension but a worse flexion in our patients. Rotation was slightly better in the previous study. The number of cases with implant loosening, dislocation or axial migration was higher in our study. This might be explained by the higher number of non-cemented prostheses.

The results of the Cobra prostheses of the single studies are compared in Table 6.

An alternative to wrist hemiarthroplasty might be total wrist arthroplasty (TWA) which has been recently reported in two case reports [25]. It could be a viable treatment modality in cases of complex DRFs combined with high grade $\mathrm{OA}$ of the carpal bones, which is a contraindication for hemiarthroplasty [13]. Moreover, it would avoid the metal-on-cartilage contact between the implant and the proximal row. Given the numerous reports of cartilage damage due to increased shearing forces after hip-hemiarthroplasty [26], TWA might reduce the potential risk of erosions in the proximal row. One the other hand, TWA is a more invasive procedure and might therefore be more prone to complications. Radioscapholunate arthrodesis is a common modality in the treatment of osteoarthritis following distal radius fractures [27]. Arthrodesis as the primary therapy for DRFs was described sporadically around the year 2000 [28-30]. However, authors agree that function-preserving measures, with the shortest possible operation time, an as less invasive technique as possible and an early rehabilitation and reintegration into daily life should be the first choice in this population. Arthrodesis may still be a secondary option. Temporary internal fixation using spanning plates is another alternative for nonreconstructable DRFs [31]. However, in elderly patients this two-stage operation on one hand is prone to a higher perioperative risk (anesthesia risk, postoperative delirium, etc.) and on the other hand delays the functional rehabilitation, which is crucial for these patients.

Conservative treatment of distal radius fractures in elderly patients over 65 years has been subject of several recent studies $[9,10]$. Most authors conclude that in an older population long-term clinical results are identical compared to surgical treatment. However, in the current cases of high-demand elderly patients with severe comminuted fractures, authors conclude that conservative treatment would have led to relevant restrictions in daily life.

Finally, another important aspect of hemiarthroplasty in elderly is that the patients have a higher risk of falling. Complex periprosthetic fractures are therefore to be expected as shown in Fig. 5a. This patient (not included in the current study) was revised by removing the cement from the proximal fragment, implantation of an allograft and osteosyntheses with a palmar plate. The follow-up $\mathrm{X}$-ray revealed bone union of the periprosthetic fracture without any signs of secondary dislocation (Fig. 5b).

Limitations of this study are the small sample size, the retrospective study design, the absence of a control group and the surgeon preferred treatment of the ulna head. Moreover, short-term follow-ups would have been useful to evaluate the early functional outcome and the re-entry into everyday activities. 
Further clinical studies are needed to confirm our recent findings and to supplement the current data with long-term results.

The use of the Cobra prosthesis in complex distal radius fractures of elderly patients led to clinically and radiologically satisfying mid-term results. We learned that an essential point is the careful evaluation of the indications using bone cement and treatment of ulnar head. A palmar approach is not recommended due to missing landmarks. Personally, the authors prefer cementing the stem and in cases of an unreconstructable DRU-joint performing a Darrach procedure as it takes less time than the Kapandji procedure and can be realized without any additional implant. Anyhow, the surgeon must always keep in mind treating a frail population associated with a higher risk for complications and revisions related to poor bone quality.

The Cobra prosthesis still does not represent a gold standard but can be regarded as a feasible salvage option for complex distal radius fractures when osteosyntheses may not be possible and non-operative treatment will lead to further functional restrictions and wrist pain during performing activities of daily life in high functional demand patients.

Supplementary Information The online version contains supplementary material available at https://doi.org/10.1007/s00402-021-04101-w.

Author contributions All authors contributed to the study conception and design. Material preparation, data collection and analysis were performed by all authors. The first draft of the manuscript was written by Stefan Benedikt and all authors commented on previous versions of the manuscript. All authors read and approved the final manuscript.

Funding Open access funding provided by University of Innsbruck and Medical University of Innsbruck. No funding was received for conducting this study.

\section{Declarations}

Conflict of interest The authors have no relevant financial or non-financial interests to disclose.

Ethics approval All procedures performed in studies involving human participants were in accordance with the ethical standards of the institutional and/or national research committee and with the 1964 Helsinki Declaration and its later amendments or comparable ethical standards. The study was approved by the Bioethics Committee of the Medical University of Innsbruck (No. 1258/2020).

Consent to participate/publish Data were obtained retrospectively. The study was approved by the institutional review board without the informed consent of data of patients due to its retrospective character. No identifying information to declare.

Open Access This article is licensed under a Creative Commons Attribution 4.0 International License, which permits use, sharing, adaptation, distribution and reproduction in any medium or format, as long as you give appropriate credit to the original author(s) and the source, provide a link to the Creative Commons licence, and indicate if changes were made. The images or other third party material in this article are included in the article's Creative Commons licence, unless indicated otherwise in a credit line to the material. If material is not included in the article's Creative Commons licence and your intended use is not permitted by statutory regulation or exceeds the permitted use, you will need to obtain permission directly from the copyright holder. To view a copy of this licence, visit http://creativecommons.org/licenses/by/4.0/.

\section{References}

1. Mauck BM, Swigler CW (2018) Evidence-based review of distal radius fractures. Orthop Clin North Am 49:211-222. https://doi. org/10.1016/j.ocl.2017.12.001

2. Neuhaus V, King JD, Jupiter JB (2012) Fixation of osteoporotic fractures in the upper limb with a locking compression plate. Acta Chir Orthop Traumatol Cech 79:404-410

3. Lampropoulou-Adamidou K, Karampinas PK, Chronopoulos E et al (2014) Currents of plate osteosynthesis in osteoporotic bone. Eur J Orthop Surg Traumatol 24:427-433. https://doi.org/ 10.1007/s00590-013-1215-0

4. Lizaur-Utrilla A, Martinez-Mendez D, Vizcaya-Moreno MF, Lopez-Prats FA (2020) Volar plate for intra-articular distal radius fracture. A prospective comparative study between elderly and young patients. Orthop Traumatol Surg Res 106:319-323. https:// doi.org/10.1016/j.otsr.2019.12.008

5. Zengin EC, Ozcan C, Aslan C et al (2019) Cast immobilization versus volar locking plate fixation of $\mathrm{AO}$ type $\mathrm{C}$ distal radial fractures in patients aged 60 years and older. Acta Orthop Traumatol Turc 53:15-18. https://doi.org/10.1016/j.aott.2018.10.005

6. Jakubietz RG, Gruenert JG, Kloss DF et al (2008) A Randomised clinical study comparing palmar and dorsal fixed-angle plates for the internal fixation of AO C-type fractures of the distal radius in the elderly. J Hand Surg Eur 33:600-604. https://doi.org/10.1177/ 1753193408094706

7. Quadlbauer S, Pezzei C, Jurkowitsch J et al (2018) Early complications and radiological outcome after distal radius fractures stabilized by volar angular stable locking plate. Arch Orthop Trauma Surg 138:1773-1782. https://doi.org/10.1007/s00402-018-3051-5

8. Rosenauer R, Pezzei C, Quadlbauer S et al (2020) Complications after operatively treated distal radius fractures. Arch Orthop Trauma Surg 140:665-673. https://doi.org/10.1007/ s00402-020-03372-z

9. Arora R, Lutz M, Deml C et al (2011) A prospective randomized trial comparing nonoperative treatment with volar locking plate fixation for displaced and unstable distal radial fractures in patients sixty-five years of age and older. J Bone Jt Surg Am 93:2146-2153. https://doi.org/10.2106/JBJS.J.01597

10. Bruyere A, Vernet P, Botero SS et al (2018) Conservative treatment of distal fractures after the age of 65: a review of literature. Eur J Orthop Surg Traumatol 28:1469-1475. https://doi.org/10. 1007/s00590-018-2150-x

11. Roux J-L (2009) La prothèse de remplacement et resurfaçage du radius distal: un nouveau concept thérapeutique. Chir Main 28:10-17. https://doi.org/10.1016/j.main.2008.11.009

12. Herzberg G, Burnier M, Marc A, Izem Y (2015) Primary wrist hemiarthroplasty for irreparable distal radius fracture in the independent elderly. J Wrist Surg 4:156-163. https://doi.org/10. 1055/s-0035-1558841

13. Herzberg G, Merlini L, Burnier M (2017) Hemi-arthroplasty for distal radius fracture in the independent elderly. Orthop Traumatol Surg Res 103:915-918. https://doi.org/10.1016/j.otsr.2017.03.029

14. Roux J-L (2011) Traitement des fractures intra-articulaires du radius distal par remplacement et resurfaçage prothétique. Rev 
Chir Orthopéd Traumatol 97:S46-S53. https://doi.org/10.1016/j. rcot.2011.03.035

15. Anger F, Legré R, Nguyen MK (2019) Results of wrist hemiarthroplasty for comminuted distal radius fractures in independent elderly people: a retrospective study on eleven patients. Hand Surg Rehabil 38:150-156. https://doi.org/10.1016/j.hansur.2018.11.004

16. Vergnenègre G, Hardy J, Mabit $\mathrm{C}$ et al (2015) Hemiarthroplasty for complex distal radius fractures in elderly patients. J Wrist Surg 4:169-173. https://doi.org/10.1055/s-0035-1558840

17. Roux J-L (2016) Wrist hemiarthroplasty for distal radius fractures. Hand 11:45S-46S. https://doi.org/10.1177/1558944716660555bt

18. Herzberg G, Walch A, Burnier M (2018) Wrist hemiarthroplasty for irreparable DRF in the elderly. Eur J Orthop Surg Traumatol 28:1499-1503. https://doi.org/10.1007/s00590-018-2228-5

19. Martins A, Lazarus $P$, Facca $S$ et al (2020) Isoelastic resurfacing prosthesis for distal radius fractures: outcomes in 24 cases with at least 2 years' follow-up. Orthop Traumatol Surg Res 106:16131618. https://doi.org/10.1016/j.otsr.2020.07.005

20. Ichihara S, Hidalgo Díaz J, Peterson B et al (2016) Distal radius isoelastic resurfacing prosthesis: a preliminary report. J Wrist Surg 5:168-168. https://doi.org/10.1055/s-0036-1580725

21. Kaiser P, Arora R (2020) Die primäre Radiusfrakturprothese bei nicht rekonstruierbaren osteoporotischen distalen Radiusfrakturen. OP Journal 36:133-138. https://doi.org/10.1055/a-1022-1622

22. Bowers WH (1985) Distal radioulnar joint arthroplasty: The hemiresection-interposition technique. J Hand Surg Am 10:169178. https://doi.org/10.1016/S0363-5023(85)80100-3

23. Pillukat T, Windolf J, van Schoonhoven J (2020) Fixateur externe am Handgelenk - temporäre Fixation. Oper Orthop Traumatol 32:396-409. https://doi.org/10.1007/s00064-020-00675-7

24. Friedman SL, Palmer AK, Short WH et al (1993) The change in ulnar variance with grip. J Hand Surg Am 18:713-716. https:// doi.org/10.1016/0363-5023(93)90325-W
25. Schmidt I (2015) Can total wrist arthroplasty be an option for treatment of highly comminuted distal radius fracture in selected patients? Preliminary experience with two cases. Case Rep Orthop 2015:1-7. https://doi.org/10.1155/2015/380935

26. Filippo M, Driessen A, Colarossi G et al (2020) Bipolar versus monopolar hemiarthroplasty for displaced femur neck fractures: a meta-analysis study. Eur J Orthop Surg Traumatol 30:401-410. https://doi.org/10.1007/s00590-019-02600-6

27. Quadlbauer S, Leixnering M, Rosenauer R et al (2020) Radioskapholunäre Arthrodese mit Entfernung des distalen Skaphoidpols von palmar. Oper Orthop Traumatol 32:455-466. https://doi.org/ 10.1007/s00064-020-00651-1

28. Kafury AA, Freeland AE, Barbieri RA (1998) Primary wrist arthrodesis in a severe intra-articular distal radial fracture. Orthopedics 21:803-805. https://doi.org/10.3928/0147-7447-19980 701-10

29. Freeland AE, Sud V, Jemison DM (2000) Early wrist arthrodesis for irreparable intra-articular distal radial fractures. Hand Surg 5:113-118. https://doi.org/10.1142/S0218810400000181

30. Terral TG, Freeland AE (1996) Early salvage reconstruction of severe distal radius fractures. Clin Orthop Relat Res 327:147-151. https://doi.org/10.1097/00003086-199606000-00019

31. Beeres FJP, Liechti R, Link B-C, Babst R (2021) Role of a spanning plate as an internal fixator in complex distal radius fractures. Oper Orthop Traumatol 33:77-88. https://doi.org/10.1007/ s00064-020-00686-4

Publisher's Note Springer Nature remains neutral with regard to jurisdictional claims in published maps and institutional affiliations. 